\title{
Strokes in young adults: epidemiology and prevention
}

\author{
This article was published in the following Dove Press journal: \\ Vascular Health and Risk Management \\ 24 February 2015 \\ Number of times this article has been viewed
}

\section{Dževdet Smajlović}

Department of Neurology, University Clinical Centre Tuzla, School of Medicine, University of Tuzla, Bosnia and Herzegovina
Correspondence: Dževdet Smajlović Department of Neurology, University Clinical Centre Tuzla, Trnovac bb, 75000 Tuzla, Bosnia and Herzegovina Email dzsmajlovic@hotmail.com
Abstract: Strokes in young adults are reported as being uncommon, comprising $10 \%-15 \%$ of all stroke patients. However, compared with stroke in older adults, stroke in the young has a disproportionately large economic impact by leaving victims disabled before their most productive years. Recent publications report an increased incidence of stroke in young adults. This is important given the fact that younger stroke patients have a clearly increased risk of death compared with the general population. The prevalence of standard modifiable vascular risk factors in young stroke patients is different from that in older patients. Modifiable risk factors for stroke, such as dyslipidemia, smoking, and hypertension, are highly prevalent in the young stroke population, with no significant difference in geographic, climatic, nutritional, lifestyle, or genetic diversity. The list of potential stroke etiologies among young adults is extensive. Strokes of undetermined and of other determined etiology are the most common types among young patients according to TOAST (Trial of Org 10172 in Acute Stroke Treatment) criteria. Prevention is the primary treatment strategy aimed at reducing morbidity and mortality related to stroke. Therefore, primary prevention is very important with regard to stroke in young adults, and aggressive treatment of risk factors for stroke, such as hypertension, smoking, and dyslipidemia, is essential. The best form of secondary stroke prevention is directed toward stroke etiology as well as treatment of additional risk factors. However, there is a lack of specific recommendations and guidelines for stroke management in young adults. In conclusion, strokes in young adults are a major public health problem and further research, with standardized methodology, is needed in order to give us more precise epidemiologic data. Given the increasing incidence of stroke in the young, there is an objective need for more research in order to reduce this burden.

Keywords: cerebrovascular diseases, age, incidence, risk factors, etiology, management

\section{Introduction}

Despite considerable improvement in primary prevention, diagnostic workup, and treatment, stroke is in second or third place on a mortality list, and projections indicate that it will remain so in the year 2020. Furthermore, stroke is a leading cause of disability. Although published reports indicate that stroke is not common in young adults, in everyday clinical practice we are often faced with acute neurologic symptoms in this age group, and stroke should be considered as the differential diagnosis. The nature and etiology of stroke in young adults is different from that in older patients, and has an influence on diagnostic evaluation and treatment, so knowledge gleaned from research in older patients cannot always be applied to young adults. Compared with stroke in older people, stroke in the young has a disproportionately large economic impact by leaving victims disabled during their most productive years. Of concern are 
data indicating an increasing incidence of stroke in younger age groups. ${ }^{1}$

When discussing the epidemiology of stroke, first we need to understand what is meant by a "young patient". To define an age cut-off is challenging and sometimes arbitrary, but previously published studies and registries commonly define young adults as those younger than 45 or 49 years. This paper provides an overview of the epidemiology and prevention of strokes in young adults. It is based on a review of populationbased, community-based, and hospital-based studies of stroke in young adults, with a focus on papers published within the last 10 years. Data used in this review were identified by a MEDLINE search using the search terms "stroke and young adults", "ischemic stroke and young adults", "hemorrhagic stroke and young adults", "epidemiology and young stroke", and "prevention and young stroke".

\section{Epidemiology of stroke in young adults}

There are many published series concerning stroke in young patients, but the data are conflicting. Comparison between studies is difficult for a number of reasons, including the methodology used, age groups, diagnostic criteria, time scale, and a change in the pathology. The proportion of first-ever stroke in young adults differs from country to country, ranging from $<5 \%$ to $20 \%$ of all strokes. ${ }^{2-4}$

\section{Incidence and proportion}

In the past 3 decades, a large number of studies have been published on the incidence of stroke in young adults. The results of these studies have been rather heterogeneous in terms of methodology and ethnicity. A systematic review on the incidence of stroke in young adults was published by Marini et al, ${ }^{5}$ who analyzed 29 studies including 3,589 patients under 45 years of age with first-ever stroke, published between 1980 and 2009. Crude rates ranged from $5.76 / 100,000$ to $39.79 / 100,000$ and standardized rates ranged from $6.14 / 100,000$ to $48.51 / 100,000$. In the same review, the proportion of ischemic strokes ranged between $21.0 \%$ and $77.9 \%$, intracerebral hemorrhage between $3.7 \%$ and $38.5 \%$, and subarachnoid hemorrhage between $9.6 \%$ and $55.4 \%$. In a recent study from Bosnia and Herzegovina, ischemic stroke among young adults was diagnosed in $61 \%$ of cases, intracerebral hemorrhage in $17 \%$, and subarachnoid hemorrhage in $22 \%{ }^{6}$

A few studies on stroke incidence in young adults have been published since 2009. A Finnish study analyzed 1,008 consecutive ischemic stroke patients aged $15-49$ years. $^{7}$
The estimated annual occurrence was 10.8 (range 8.4 to 13.0) per 100,000 , increasing exponentially with advancing age. Groppo et al reported a crude incidence of stroke of 12.1 cases per 100,000 among young Italians. ${ }^{8}$

Racial and ethnic differences in risk of stroke are widely recognized, and these differences are even greater in younger populations. The racial composition of a study population is an important component of incidence variability. The Northern Manhattan Study showed that young blacks and Hispanics have a greater incidence of stroke than young whites. ${ }^{9}$ In another study in Florida, young black adults and Hispanics had a significantly higher hospitalization rate for stroke than whites. ${ }^{10}$ A high stroke incidence (70/100,000) in the 35-44 year old age group has also been observed in Japan, ${ }^{11}$ as well as among young and middle-aged blacks in the USA, who have a two- to five-fold higher stroke risk compared with whites. ${ }^{12}$ The incidence of stroke in the young has been reported to be higher for men than for women older than 35 years of age in community-based and populationbased studies. ${ }^{13,14}$ On the other hand, one population-based study in Italy reported an increased stroke incidence among women under 30 years of age. ${ }^{15}$

\section{Risk factors}

Modifiable risk factors are the same for both younger and older age groups. However, the prevalence of these risk factors is not the same in these two age groups. Hypertension, heart disease (including atrial fibrillation), and diabetes mellitus are the most common risk factors among the elderly. ${ }^{6}$ In contrast, among 1,008 young stroke patients in Finland, the most common vascular risk factors were dyslipidemia (60\%), smoking (44\%), and hypertension (39\%). ${ }^{7}$ In another study, Putaala et a ${ }^{16}$ investigated the distribution of vascular risk factors in 3,944 young stroke patients from three distinct geographic regions in Europe. The three most frequent risk factors were current smoking (49\%), dyslipidemia (46\%), and hypertension (36\%). ${ }^{16}$ Furthermore, among 990 young stroke patients with first-ever ischemic stroke, those without well documented risk factors had less frequent recurrent ischemic strokes and noncerebrovascular arterial events, as well as lower long-term mortality rates than those with one or more risk factors. ${ }^{17}$ The investigators concluded that numbers of risk factors add independent prognostic information regarding noncerebrovascular events and mortality in young adults.

Classical vascular risk factors, including hypertension, dyslipidemia, and cigarette smoking have also been reported to be common in young stroke patients in the 
Table I Studies on stroke etiology in young patients

\begin{tabular}{lllllll}
\hline Reference & Country & LAA & CE & SVD & ODE & UE \\
\hline Cerrato et al $^{20}$ & Italy & 16 & 24 & 17 & 19 & 24 \\
Nedeltcher et al $^{2}$ & Switzerland & 4 & 30 & 9 & 24 & 33 \\
Rasura et al $^{15}$ & Italy & 12 & 34 & 3 & 28 & 24 \\
Varona et al $^{3}$ & Spain & 20 & 18 & 5 & 22 & 36 \\
Jovanovic et al $^{21}$ & Serbia & 8 & 20 & 22 & 24 & 26 \\
Putaala et al $^{7}$ & Finland & 8 & 20 & 14 & 26 & 33 \\
Spengos and $_{\text {Vemmos }}^{22}$ & Greece & 9 & 13 & 17 & 27 & 34 \\
Smajlovic et al $^{6}$ & Bosnia and & 15 & 10 & 26 & 9 & 40 \\
Tancredi et al $^{23}$ & Herzegovina & & & & & \\
Yesilot Barlas et al $^{24}$ & Italy & 9 & 19 & 16 & 29 & 27 \\
\hline
\end{tabular}

Note: All numbers are percentages.

Abbreviations: LAA, large artery atherosclerosis; CE, cardiac embolism; SVD, small vessel disease; ODE, other determined etiology; UE, undetermined etiology.

People's Republic of China and New Zealand. ${ }^{18,19}$ According to the presented results, the prevalence of these risk factors for stroke in young adults is similar around the world. Therefore, the earlier thesis that the proportion of stroke risk factors depends on geographic, climatic, nutritional, lifestyle, or genetic diversity, is not entirely correct.

\section{Etiology}

The etiology of ischemic stroke in young adults and adolescents is diverse and varies according to age and geographic region. In the past 10 years, there have been many published series of stroke etiology in young patients, and Table 1 summarizes these reports. The TOAST (Trial of Org 10172 in Acute Stroke Treatment) criteria for classification of acute ischemic stroke are the most commonly used. ${ }^{25}$

Despite a systematic diagnostic approach and more accurate diagnostic tools becoming available in the form of vascular imaging and hematologic and genetic studies, stroke of undetermined etiology was the most common etiology among young stroke patients, with the exception of two studies. ${ }^{2,23}$ The high number of young stroke patients with undetermined etiology may be explained in part by the insufficient extent and timing of the investigations. On the other hand, the TOAST classification is not perfect, and can lead to overestimation of patients with stroke of undetermined etiology, mainly because patients with two or more potential etiologies fall into this group. This group also includes patients with incomplete investigation and those with no evident cause despite extensive evaluation. Therefore, a newer classification system for more accurate etiologic subtyping of ischemic stroke, like A-S-C-O ${ }^{26}$ might have an influence on reducing the high numbers of strokes being identified as of undetermined etiology. Stroke of other determined etiology collectively account for $20 \%-30 \%$ of cases of young stroke. A wide variety of different and uncommon causes of stroke in young adults is presented in Table 2 .

Cervicocephalic arterial dissection is the second most common lesion of the cervical arteries after atherosclerosis, and rank first or second with regard to all etiologies of ischemic stroke in young adults (up to $25 \%$ of cases). ${ }^{23,27}$ Moyamoya disease affects mainly Asian people (representing $6 \%-15 \%$ of cases of nonatherosclerotic vasculopathy), but is described throughout the world. The link between migraine and ischemic stroke has been known for years. The risk is particularly pronounced among young women having migraine with aura, and is multiplied among smokers and those using oral contraception. ${ }^{28}$ Inherited coagulation disorders do not have a significant role in stroke among the young, with the exception of antiphospholipid antibody syndrome. In one systematic review, antiphospholipid antibodies, particularly lupus anticoagulant, were an independent risk factor for ischemic stroke in young adults in five of six studies. ${ }^{29}$

Rare genetic and hereditary diseases, such as Fabry disease, cerebral autosomal dominant arteriopathy with subcortical infarcts and leukoencephalopathy (CADASIL), and mitochondrial encephalopathy with lactic acidosis and stroke-like episodes (MELAS), must be considered in the differential diagnosis of young patients with ischemic stroke. Vasculitides of the central nervous system are complex diseases and often reminded when differential diagnosis of stroke in young adults is discussed. Primary cerebral angiitis is twice as common in middle-aged men than in women, ${ }^{30}$ and vasculitis related to infection is more common in developing countries and in regions with a higher prevalence of human immunodeficiency virus. ${ }^{31}$

Cardioembolic stroke accounts for up to one third of ischemic strokes in young adults (Table 1). However, it is often more difficult to diagnose. The causes of cardiogenic embolism are different, and 30 years ago Hart developed the concept of major and minor sources of cardioembolism (Table 3). ${ }^{32}$ One of the most commonly debated questions is the role of patent foramen ovale (PFO) in cardioembolism. The prevalence of PFO in the general population is about $20 \%$, and is even higher in young stroke patients (up to 50\%). Several studies have confirmed an association between PFO and cryptogenic stroke, but the finding of a PFO was incidental in one third of these patients. ${ }^{33} \mathrm{~A}$ recent meta-analysis of PFO closure trials suggests potential but uncertain benefit of PFO closure over medical management. ${ }^{34}$ The limitation of these trials is their small sample size, and the management of cryptogenic stroke in young adults with PFO remains unclear. 
Table 2 Uncommon causes of stroke in young adults

\begin{tabular}{|c|c|}
\hline $\begin{array}{l}\text { Nonatherosclerotic } \\
\text { angiopathies }\end{array}$ & $\begin{array}{l}\text { Cervicocephalic arterial dissection } \\
\text { Cerebral amyloid angiopathy }\end{array}$ \\
\hline & $\begin{array}{l}\text { Moyamoya disease } \\
\text { Fibromuscular dysplasia } \\
\text { Reversible cerebral vasoconstriction syndrome } \\
\text { Susac's syndrome } \\
\text { Sneddon's syndrome } \\
\text { Migraine-induced stroke }\end{array}$ \\
\hline $\begin{array}{l}\text { Hematologic } \\
\text { conditions }\end{array}$ & $\begin{array}{l}\text { Hypercoagulable state due to deficiencies of } \\
\text { protein S, protein C, or antithrombin; factorV Leiden } \\
\text { mutation, prothrombin gene G202I0A mutation } \\
\text { Acquired hypercoagulable state (eg, cancer, } \\
\text { pregnancy, hormonal contraceptive use, exposure } \\
\text { to hormonal treatments such as anabolic steroids } \\
\text { and erythropoietin, nephrotic syndrome) } \\
\text { Antiphospholipid syndrome } \\
\text { Hyperhomocysteinemia } \\
\text { Sickle cell disease } \\
\text { Myeloproliferative disorders (eg, leukemia, } \\
\text { lymphoma) }\end{array}$ \\
\hline Genetic & $\begin{array}{l}\text { Fabry disease } \\
\text { CADASIL } \\
\text { MELAS } \\
\text { Marfan syndrome } \\
\text { Neurofibromatosis } \\
\text { Sturge-Weber disease }\end{array}$ \\
\hline $\begin{array}{l}\text { Inflammatory and } \\
\text { infectious }\end{array}$ & $\begin{array}{l}\text { Vasculitis (primary angitis of the CNS, Sjögren } \\
\text { syndrome, Wegener's granulomatosis) } \\
\text { Temporal arteritis } \\
\text { Takayasu disease } \\
\text { Behçet's syndrome } \\
\text { Neurosarcoidosis } \\
\text { Neurocysticercosis } \\
\text { HIV } \\
\text { Varicella zoster virus } \\
\text { Neurosyphilis } \\
\text { Tuberculous meningitis }\end{array}$ \\
\hline
\end{tabular}

Abbreviations: CADASIL, cerebral autosomal dominant arteriopathy with subcortical infarcts and leukoencephalopathy; CNS, central nervous system; HIV, human immunodeficiency virus; MELAS, mitochondrial encephalomyopathy, lactic acidosis, and stroke-like episodes.

Large-artery atherosclerosis has been shown to be an infrequent cause of ischemic stroke in young adults, accounting for less than $10 \%$ of cases. However, the results of a couple of studies show a higher incidence of atherosclerotic stroke, mainly due to the presence of multiple

Table 3 Cardiac sources of embolism

\begin{tabular}{ll}
\hline Major risk sources & Minor risk sources \\
\hline Atrial fibrillation & Patent foramen ovale \\
Prosthetic heart valves & Atrial septal aneurysm, recent \\
Myocardial infarction & Spontaneous echo contrast \\
Intracardiac thrombus & Mitral valve prolapse \\
Mitral stenosis & Mitral annular calcification \\
Atrial myxoma & Calcific aortic stenosis \\
Dilated cardiomyopathy (EF $<35 \%)$ & Ventricular akinesia (EF $>35 \%)$ \\
Left ventricular aneurysm & \\
Infective endocarditis & \\
\hline
\end{tabular}

Abbreviation: $\mathrm{EF}$, ejection fraction. modifiable risk factors, such as hypertension, cigarette smoking, and hyperlipidemia., ${ }^{3,620}$ The large studies indicate that hemorrhagic stroke (subarachnoid and intracerebral) accounts for up to $50 \%$ of all strokes that occur under the age of 45 years, with reported incidence rates in the range of 3-6/100,000/year for subarachnoid hemorrhage and $2-7 / 100,000$ year for intracerebral hemorrhage. ${ }^{35,36}$ In general, the etiology of intracerebral hemorrhage in young patients is similar to that in those older than 45 years, except for an overrepresentation of arteriovenous malformation, cavernoma, drug abuse, and bleeding disorders early in life. Hypertension remains a frequent cause of intracerebral hemorrhage in both younger and older individuals, and the majority of hemorrhages are lobar. In young adults with intracerebral hemorrhage, the possibility of illicit cocaine or other drug abuse must be considered. In one study, cocaine and amphetamine abuse was associated with an increased rate of hemorrhagic stroke. ${ }^{37}$ Aneurysms in young adults show the same anatomic locations and clinical findings as in older patients, and subarachnoid hemorrhage before and after the age of 45 years is diagnosed and managed in the same manner.

\section{Prevention of strokes in young adults}

Stroke is the second/third leading cause of death worldwide. It caused an estimated 5.7 million deaths in 2005 , and the global number of deaths is projected to rise to 6.5 million in 2015 and 7.8 million in $2030 .^{38}$ Although some studies have suggested an increase in the incidence of stroke in young adults, the prognosis of these patients is generally considered to be favorable. However, a recent study by Rutten-Jacobs et al indicates that the long-term mortality after stroke in young adults is higher than expected, suggesting a need for further research to improve stroke prevention in this age group. ${ }^{39}$ Furthermore, stroke in young patients has major long-term socioeconomic consequences. In one study, it was estimated that the average cost of a hospital stay for a young stroke patient was US\$34,886 for ischemic stroke, US $\$ 146,307$ for subarachnoid hemorrhage, and US\$94,482 for intracerebral hemorrhage. ${ }^{40}$

Prevention is the primary treatment strategy aimed at reducing the morbidity and mortality related to stroke, and adequate treatment, control of risk factors, and lifestyle changes can prevent up to $50 \%$ of strokes. A number of recommendations on the management and prevention of stroke and transient ischemic attack have been published. The guidelines of the European Stroke Organization (published in 2008 and updated in 2009) $)^{41}$ and the very recent guidelines 
for the primary prevention of stroke from the American Heart Association/American Stroke Association ${ }^{42}$ cover stroke prevention in detail. However, there are no specific recommendations or guidelines for primary or secondary stroke prevention in young adults. In general, prevention strategies are similar for younger and older patients.

\section{Primary stroke prevention}

Primary prevention aims to reduce the risk of stroke in asymptomatic subjects. It is focused on identifying and managing known vascular risk factors, such as arterial hypertension, disorders of lipid metabolism, and diabetes mellitus, and non-drug strategies and lifestyle changes, including quitting smoking, limiting alcohol consumption, reducing elevated body weight, increasing regular aerobic physical activity, and adopting a healthy diet with more fruit and vegetables and less salt. ${ }^{43}$

Hypertension is the risk factor that most significantly correlates with stroke and plays a role in more than $50 \%$ of episodes of stroke worldwide. High blood pressure can lead to occlusive stroke, as well as intracerebral or subarachnoid hemorrhage, and correlates with the risk of first-ever stroke and recurrent stroke. A summary of the recent clinical trial data confirms that antihypertensive therapy substantially reduces the risk of any type of stroke, as well as stroke-related death and disability. ${ }^{44}$ Treatment should be individualized and target blood pressure is $<140 / 90 \mathrm{mmHg}$. The risk of stroke is two to six times higher in diabetic patients; however, diabetes mellitus is not a common risk factor in young adults. Glycemic control reduces microvascular complications, but there is no evidence that improved glycemic control reduces the incidence of stroke in patients with diabetes mellitus. In younger diabetics, treatment should be targeted toward control of blood pressure $(<130 / 80 \mathrm{mmHg})$ and treatment of hyperlipidemia, especially in individuals with additional risk factors. Blood lipid abnormalities are another risk factor that should be corrected as part of primary prevention in terms of overall cardiovascular risk. Therapeutic lifestyle changes should be the first strategy. Treatment with statins is recommended in patients estimated to have a high 10-year risk for cardiovascular events. ${ }^{45}$ Epidemiologic data indicate a strong relationship between cigarette smoking and ischemic stroke and subarachnoid hemorrhage, particularly in the young age group. ${ }^{46,47}$ Cigarette smoking also has a synergistic effect via its link with other vascular risk factors, such as hypertension, diabetes mellitus, use of oral contraceptives, and physical inactivity. Stopping smoking mitigates the risk of stroke, as it does with other conditions such as coronary disease, peripheral vascular disease, and death from vascular causes.
The prevalence of current smoking in developed countries is decreasing, but in developing countries is still high. Therefore, smoking cessation programs need to be more widespread and effective in developing countries. Smoking cessation programs and changes in legislation to reduce the opportunities to smoke need to be a priority for policymakers to save millions of lives and reduce smoking-related morbidity. ${ }^{48}$ Two meta-analyses indicate that a diet rich in fruit and vegetables and with a reduced salt content can reduce the risk of stroke. ${ }^{49,50}$ The effect of physical activity and exercise on health and disease has been the focus of much research attention. A meta-analysis of 23 studies concluded that there was strong evidence that moderate and high levels of physical activity were associated with a reduced risk of total, ischemic, and hemorrhagic stroke. ${ }^{51}$ The mechanism by which exercise decreases stroke risk is likely to be multifactorial and to include blood pressure, lipid, and weight control.

\section{Secondary stroke prevention}

It has been shown that $3 \%-4 \%$ of all patients who experience a stroke will experience a second stroke. The cumulative 5-year recurrence rate among young adults was $9.4 \%$ for nonfatal or fatal ischemic stroke, and these individuals, despite their young age, were at increased risk of recurrent arterial events, predicted by mostly modifiable baseline risk factors. ${ }^{52}$ In a very recent study, Aarnio et al analyzed long-term mortality in 970 consecutive young and middle-aged stroke patients. ${ }^{53}$ The observed mortality was seven-fold higher than the expected mortality, and was particularly high among patients who experienced a recurrent stroke. The authors concluded that there is a need for more robust primary and secondary prevention of stroke in young adults.

For secondary stroke prevention, aimed at reducing the risk of another stroke, identification of the etiologic mechanism of the initial stroke and the presence of any additional risk factors is most important. It consists of optimal treatment of vascular risk factors (arterial hypertension, hyperlipidemia, diabetes mellitus, and cardiac disease), administering antiplatelet or anticoagulant therapy, and if indicated, invasive surgical or endovascular therapeutic procedures. An integral part of this is lifestyle changes, emphasizing regular physical activity, a diet low in salt and saturated fat and high in fruit and vegetables, reducing overweight, and quitting smoking and heavy use of alcohol. ${ }^{41}$ Adequate longterm secondary prevention was associated with a reduced risk of death and recurrent stroke and improved outcome in routine settings. ${ }^{54,55}$ Hypertension is the single most important vascular risk factor for stroke. In practice, young adults 
who have had a stroke should have tight control of blood pressure to $\leq 130 / 80 \mathrm{mmHg}$, with the clinician's choice of antihypertensive regimen. Especially for these young stroke patients, evaluation for the etiology of uncontrollable hypertension such as renal artery stenosis, pheochromocytoma, hyperaldosteronism, or systemic vasculitis may be indicated in some cases. The benefit of statins in young stroke patients with predominantly nonatherosclerotic stroke etiologies remains controversial; however, in young patients with cryptogenic stroke, statin therapy was associated with fewer recurrent vascular events. ${ }^{56}$ It is well established that diabetes mellitus is an independent risk factor for stroke, while data on stroke recurrence are more sparse. Diabetic stroke patients, both young adults and the elderly, have higher mortality, a less favorable outcome, more severe disability, and slower recovery after a stroke, as well as higher rates of stroke recurrence within 6 months. ${ }^{57-59}$ These patients also have a high prevalence of other comorbid risk factors, such as hypertension, hyperlipidemia, obesity, and insulin resistance, to elevate their risk of stroke. Therefore, more aggressive treatment of these comorbidities is required.

In stroke patients with defined large-artery atherosclerosis or small-vessel disease, risk factors should be modified and antiplatelet drugs are recommended, along with carotid endarterectomy or percutaneous transluminal angioplasty in selected patients. According to the guidelines, acetylsalicylic acid (ASA) should be a first-choice antiplatelet drug in secondary prevention. ${ }^{41}$ First-choice treatment can be ASA in combination with dipyridamole (25/200 mg twice daily) or clopidogrel monotherapy ( $75 \mathrm{mg}$ /day). The combination of ASA + clopidogrel is not recommended in secondary stroke prevention except in the case of the coincidence of stroke and a recent myocardial infarction or status post-coronary stenting. Clopidogrel $75 \mathrm{mg} /$ day is considered a first-choice treatment, especially in patients with ASA intolerance. In patients with cardioembolic stroke due to atrial fibrillation or other cardioembolism, warfarin (International Normalized Ratio [INR] 2-3) is indicated for secondary prevention. For patients unable to take oral anticoagulants and those who refuse all forms of anticoagulation, ASA + clopidogrel combination therapy, or less effectively only ASA is recommended. ${ }^{60,61}$ Novel oral anticoagulants (NOAC; thrombin and factor $\mathrm{X}$ inhibitors) have the added benefit of not requiring INR monitoring. Clinical studies have demonstrated noninferiority of all NOAC tested in comparison with warfarin, with better safety and a reduced risk of intracerebral hemorrhage. NOAC can be also used for secondary prevention of cardioembolic stroke in patients with stroke recurrence despite appropriate treatment with warfarin. ${ }^{61,62}$ Although a detailed review of the prevention of stroke in patients with specific etiologies is outside the scope of this article, a few common conditions can be mentioned. For lack of results from clinical trials on stroke prevention in patients with PFO, antiplatelet treatment is considered appropriate for stroke patients with isolated PFO and percutaneous closure of PFO is not recommended. ${ }^{63}$ In stroke patients with cervicocephalic arterial dissection, anticoagulation is not recommended over antiplatelet therapy. ${ }^{64}$ Patients with ischemic stroke of unclear etiology and under 45 years of age must be tested for thrombophilia. Anticoagulant therapy is normally indicated in the event of a proven deficiency of antithrombin III, protein $\mathrm{C}$, or protein $\mathrm{S}$, as well as resistance to activated protein $\mathrm{C}$ (factor $\mathrm{V}$ Leiden). ASA may be considered as a preventive treatment in patients with antiphospholipid antibody positivity after a first ischemic stroke. Oral anticoagulants for an INR of 2-3 are recommended for patients who meet the criteria for antiphospholipid syndrome. ${ }^{65}$ Migraine with aura is associated with a six to eight-fold increased risk of stroke in patients under the age of 45 years, but future stroke occurrence remains unclear. There is no definite guideline for use of antiplatelet/ antithrombotic therapy in stroke prevention for women with a history of pregnancy-related stroke. Pregnant women with stroke or transient ischemic attack may be considered for treatment with unfractionated or low molecular weight heparin throughout the first trimester, followed by low-dose ASA for the remainder of the pregnancy, if a high-risk thromboembolic condition is ruled out. ${ }^{65}$ In ischemic stroke of undetermined origin, antiplatelet drugs are recommended as the first-line treatment, and anticoagulants can be used when strokes recur despite treatment with antiplatelet drugs. One of the main problems in secondary stroke prevention is long-term use of secondary prevention medications following stroke, because up to one third of stroke patients discontinued one or more such medications within 1 year of hospital discharge. ${ }^{66}$ Leistner et al compared the quality of secondary prevention consisting of usual care versus a stepwise modeled support program (outpatient appointments with a combination of educational and behavioral strategies) ${ }^{67}$ and found that control of risk factors remains unsatisfactory in usual care and a support program leads to major improvement of secondary prevention.

\section{Conclusion}

Stroke in young adults is a major public health problem, and further research using standardized methodology is needed. Future studies should be multicenter in design, with a specific 
definition of the term "young adults" and specific diagnostic and classification criteria in order to give us more precise epidemiologic data. These studies will provide clarity by enabling comparison of incidence rates between countries and trends over time, along with insights into underlying etiologic mechanisms. Prevention is the primary treatment strategy, aimed at reducing morbidity and mortality related to young stroke, but there are no specific recommendations or guidelines. In the near future, organizations such as the World Stroke Organization, the European Stroke Organization, and the American Heart and Stroke Association should make an effort to publish recommendations or a guideline for the prevention and treatment of stroke in young adults. Given the increasing incidence of stroke in the young, there is an objective need for more research in order to reduce this burden.

\section{Disclosure}

The author reports no conflicts of interest in this work.

\section{References}

1. Kissela BM, Khoury JC, Alwell K, et al. Age at stroke: temporal trends in stroke incidence in a large, biracial population. Neurology. 2012;79: 1781-1787.

2. Nedeltchev K, der Maur TA, Georgiadis D, et al. Ischaemic stroke in young adults: predictors of outcome and recurrence. J Neurol Neurosurg Psychiatry. 2005;76:191-195.

3. Varona JF, Guerra JM, Bermejo F, Molina JA, Gomez de la Camara. Causes of ischemic stroke in young adults, and evolution of the etiological diagnosis over the long term. Eur Neurol. 2007;57: 212-218.

4. George MG, Tong X, Kuklina EV, Labarthe DR. Trends in stroke hospitalizations and associated risk factors among children and young adults, 1995-2008. Ann Neurol. 2011;70:713-721.

5. Marini C, Russo T, Felzani G. Incidence of stroke in young adults: a review. Stroke Res Treat. 2011;2011:535672.

6. Smajlović DŽ, Salihović D, Ibrahimagić OĆ, Sinanović O. Characteristics of stroke in young adults in Tuzla Canton, Bosnia and Herzegovina. Coll Antropol. 2013;37:515-519.

7. Putaala J, Metso AJ, Metso TM, et al. Analysis of 1008 consecutive patients aged 15 to 49 with first-ever ischemic stroke: the Helsink Young Stroke Registry. Stroke. 2009;40:1195-1203.

8. Groppo E, De Gennaro R, Granieri G, et al. Incidence and prognosis of stroke in young adults: a population-based study in Ferrara, Italy. Neurol Sci. 2012;33:53-58.

9. Jacobs BS, Boden-Albala B, Lin IF, Sacco RL. Stroke in the young in the Northern Manhattan Stroke Study. Stroke, 2002;33: 2789-2793.

10. Barnett Pathak E, Sloan MA. Recent racial/ethnic disparities in stroke hospitalization and outcomes for young adults in Florida, 2001-2006. Neuroepidemiology. 2009;32:302-311.

11. Morikawa Y, Nakagawa H, Naruse Y, et al. Trends in stroke incidence and acute case fatality in a Japanese rural area: the Oyabe study. Stroke. 2000;31:1583-1587.

12. Kissela B, Schneider A, Kleindorfer D, et al. Stroke in a biracial population: the excess burden of stroke among blacks. Stroke. 2004;35: 426-431.

13. Lauria G, Gentile M, Fassetta G, et al. Incidence and prognosis of stroke in the Belluno Province, Italy: first-year results of a community-based study. Stroke. 1995;26:1787-1793.
14. Vibo R, Körv J, Roose M. The third stroke registry in Tartu, Estonia: decline of stroke incidence and 28-day case fatality rate since 1991. Stroke. 2005;36:2544-2548.

15. Rasura M, Spalloni A, Ferrari M, et al. A case series of young stroke in Rome. Eur J Neurol. 2006;13:146-152.

16. Putaala J, Yesilot N, Waje-Andreassen U, et al. Demographic and geographic vascular risk factor differences in European young adults with ischemic stroke: the 15 Cities Young Stroke Study. Stroke. 2012;43: 2624-2630.

17. Putaala J, Haapaniemi E, Kaste M, Tatlisumak T. How does number of risk factors affect prognosis in young patients with ischemic stroke? Stroke. 2012;43:356-361.

18. Zhang YN, He L. [Risk factors study of ischemic stroke in young adults in Southwest China]. Sichuan Da Xue Xue Bao Yi Xue Ban. 2012;43: 553-557. Chinese.

19. Wu TY, Kumar A, Wong EH. Young ischaemic stroke in South Auckland: a hospital-based study. N Z Med J. 2012;125:47-56.

20. Cerrato P, Grasso M, Imperiale D, et al. Stroke in young patients: etiopathogenesis and risk factors in different age classes. Cerebrovasc Dis. 2004;18:154-159.

21. Jovanovic DR, Beslac-Bumbasirevic L, Raicevic R, Zidverc-Trajkovic J, Ercegovac MD. Etiology of ischemic stroke among young adults of Serbia. Vojnosanit Pregl. 2008;65:803-809.

22. Spengos K, Vemmos K. Risk factors, etiology, and outcome of firstever ischemic stroke in young adults aged 15 to 45 - the Athens Young Stroke Registry. Eur J Neurol. 2010;17:1358-1364.

23. Tancredi L, Martinelli Boneschi F, Braga M, et al. Stroke care in young patients. Stroke Res Treat. 2013;2013:715380.

24. Yesilot Barlas N, Putaala J, Waje-Andreassen U, et al. Etiology of first ever ischaemic stroke in European young adults: the 15 Cities Young Stroke Study. Eur J Neurol. 2013;20:1431-1439.

25. Adams HP Jr, Bendixen BH, Kappelle LJ, et al. Classification of subtype of acute ischemic stroke. Definitions for use in a multicenter clinical trial. TOAST. Trial of Org 10172 in Acute Stroke Treatment. Stroke. $1993 ; 24: 35-41$.

26. Amarenco P, Bogousslavsky J, Caplan LR, Donnan GA, Hennerici MG. New approach to stroke subtyping: the A-S-C-O (phenotypic) classification of stroke. Cerebrovasc Dis. 2009;27:502-508.

27. Mackey J. Evaluation and management of stroke in young adults. Continuum (Minneap Minn). 2014;20:352-369.

28. Bousser MG, Welch KM. Relation between migraine and stroke. Lancet Neurol. 2005;4:533-542.

29. Brey RL. Antiphospholipid antibodies in young adults with stroke. J Thromb Thrombolysis. 2005;20:105-112.

30. Birnbaum J, Hellmann DB. Primary angiitis of the central nervous system. Arch Neurol. 2009;66:704-709.

31. Onwuchekwa AC, Onwuchekwa RC, Asekomeh EG. Stroke in young Nigerian adults. J Vasc Nurs. 2009;27:98-102.

32. Hart RG. Cardiogenic embolism to the brain. Lancet. 1992;339: 589-594.

33. Alsheikh-Ali AA, Thaler DE, Kent DM. Patent foramen ovale in cryptogenic stroke: incidental or pathogenic? Stroke. 2009;40: 2349-2355.

34. Kitsios GD, Thaler DE, Kent DM. Potentially large yet uncertain benefits: a metaanalysis of patent foramen ovale closure trials. Stroke. 2013;44:2640-2643.

35. Marini C, Totaro R, De Santis F, Ciancarelli I, Baldassarre M, Carolei A. Stroke in young adults in the community-based L'Aquila registry: incidence and prognosis. Stroke. 2001;32:52-56.

36. Jacobs BS, Boden-Albala B, Lin IF, Sacco RL. Stroke in the young in the Northern Manhattan Stroke Study. Stroke. 2002;33: 2789-2793.

37. Westover AN, McBride S, Haley RW. Stroke in young adults who abuse amphetamines or cocaine: a population-based study of hospitalized patients. Arch Gen Psychiatry. 2007;64:495-502.

38. Strong K, Mathers C, Bonita R. Preventing stroke: saving lives around the world. Lancet Neurol. 2007;6:182-187. 
39. Rutten-Jacobs LC, Arntz RM, Maaijwee NA, et al. Long-term mortality after stroke among adults aged 18 to 50 years. JAMA. 2013;309:1136-1144.

40. Ellis C. Stroke in young adults. Disabil Health J. 2010;3:222-224.

41. European Stroke Organisation (ESO) Executive Committee; ESO Writing Committee: Guidelines for management of ischaemic stroke and transient ischaemic attack 2008. Cerebrovasc Dis. 2008;25: 457-507.

42. Meschia JF, Bushnell C, Boden-Albala B, et al. Guidelines for the Primary Prevention of Stroke. A Statement for Healthcare Professionals from the American Heart Association/American Stroke Association. Stroke. 2014;45:3754-3832.

43. Polívka J, Rohan V, Ševčík P, Polívka J Jr. Personalized approach to primary and secondary prevention of ischemic stroke. EPMA J. 2014;5:9.

44. Gaciong Z, Siński M, Lewandowski J. Blood pressure control and primary prevention of stroke: summary of the recent clinical trial data and meta-analyses. Curr Hypertens Rep. 2013;15:559-574.

45. Stone NJ, Robinson J, Lichtenstein AH, et al. 2013 ACC/AHA guideline on the treatment of blood cholesterol to reduce atherosclerotic cardiovascular risk in adults: a report of the American College of Cardiology/American Heart Association Task Force on Practice Guidelines. Circulation. 2014;129 Suppl 2:S1-S45.

46. Shinton R, Beevers G. Meta-analysis of relation between cigarette smoking and stroke. BMJ. 1989;298:789-794.

47. Feigin V, Parag V, Lawes CM, et al; Asia Pacific Cohort Studies Collaboration. Smoking and elevated blood pressure are the most important risk factors for subarachnoid hemorrhage in the Asia-Pacific region: an overview of 26 cohorts involving 306,620 participants. Stroke. 2005;36:1360-1365.

48. Feigin VL, Krishnamurthi R. Stroke prevention in the developing world. Stroke. 2011;42:3655-3658.

49. He FJ, Nowson CA, MacGregor GA. Fruit and vegetable consumption and stroke: metaanalysis of cohort studies. Lancet. 2006;367: 320-326.

50. Li XY, Cai XL, Bian PD, Hu LR. High salt intake and stroke: meta-analysis of the epidemiologic evidence. CNS Neurosci Ther. 2012;18:691-701.

51. Lee CD, Folsom AR, Blair SN. Physical activity and stroke risk. A meta-analysis. Stroke. 2003;34:2475-2482.

52. Putaala J, Haapaniemi E, Matseo AJ, et al. Recurent ischemic events in young adults after first-ever ischemic stroke. Ann Neurol. 2010;68:661-671.

53. Aarnio K, Haapaniemi E, Melkas S, Kaste M, Tatlisumak T, Putaala J. Long-term mortality after first-ever and recurrent stroke in young adults. Stroke. 2014;45:2670-2676.

54. Åsberg S, Henriksson KM, Farahmand B, et al. Ischemic stroke and secondary prevention in clinical practice: a cohort study of 14,529 patients in the Swedish Stroke Register. Stroke. 2010;41: $1338-1342$.
55. Palnum KH, Mehnert F, Andersen G, et al. Use of secondary medical prophylaxis and clinical outcome among patients with ischemic stroke: a nationwide follow-up study. Stroke. 2012;43:802-807.

56. Putaala J, Haapaniemi E, Kaste M, Tatlisumak T. Statins after ischemic stroke of undetermined etiology in young adults. Neurology. 2011;77:426-430

57. Smajlović Dž, Salihović D, Ibrahimagić OĆ, Sinanović O, Burina A. Stroke in patients with diabetes mellitus: a hospital based study. Med Arh. 2006;60(6 Suppl 2):63-65.

58. Jia Q, Zhao X, Wang C, et al. Diabetes and poor outcomes within 6 months after acute ischemic stroke: the China National Stroke Registry. Stroke. 2011;42:2758-2762.

59. Putaala J, Liebkind R, Gordin D, et al. Diabetes mellitus and ischemic stroke in the young: clinical features and longterm prognosis. Neurology. 2011;76:1831-1837.

60. Furie KL, Goldstein LB, Albers GW, et al; on behalf of the American Heart Association Stroke Council, Council on Quality of Care and Outcomes Research, Council on Cardiovascular Nursing, Council on Clinical Cardiology, and Council on Peripheral Vascular Disease. Oral Antithrombotic Agents for the Prevention of Stroke in Nonvalvular Atrial Fibrillation: a Science Advisory for Healthcare Professionals from the American Heart Association/American Stroke Association. Stroke. 2012;43:3442-3453.

61. Lip GY, Bongiorni MG, Dobreanu D, et al; Scientific Initiative Committee, European Heart Rhythm Association. Novel oral anticoagulants for stroke prevention in atrial fibrillation: results of the European Heart Rhythm Association survey. Europace. 2013;15:1526-1532.

62. Fuentes B, Gállego J, Gil-Nunez A, et al. Guidelines for the preventive treatment of ischaemic stroke and TIA (II). Recommendations according to aetiological sub-type. Neurología. 2014;29:168-183.

63. O'Gara PT, Messe SR, Tuzcu EM, Catha G, Ring JC; American Heart Association. Percutaneous device closure of patent foramen ovale for secondary stroke prevention: a call for completion of randomized clinical trials: a science advisory from the American Heart Association/ American Stroke Association and the American College of Cardiology Foundation. Circulation. 2009;119:2743-2747.

64. Menon R, Kerry S, Norris JW, Markus HS. Treatment of cervical artery dissection: a systematic review and meta-analysis. J Neurol Neurosurg Psychiatry. 2008;79:1122-1127.

65. Furie KL, Kasner SE, Adams RJ, et al. Guidelines for the prevention of stroke in patients with stroke or transient ischemic attack: a guideline for healthcare professionals from the American Heart Association/ American Stroke Association. Stroke. 2011;42:227-276.

66. Bushnell CD, Olson DM, Zhao X, et al. Secondary preventive medication persistence and adherence 1 year after stroke. Neurology. 2011;77:1182-1190.

67. Leistner S, Benik S, Laumeier I, et al. Secondary prevention after minor stroke and TIA - usual care and development of a support program. PLoS One. 2012;7:e49985.
Vascular Health and Risk Management

\section{Publish your work in this journal}

Vascular Health and Risk Management is an international, peerreviewed journal of therapeutics and risk management, focusing on concise rapid reporting of clinical studies on the processes involved in the maintenance of vascular health; the monitoring, prevention and treatment of vascular disease and its sequelae; and the involvement of

\section{Dovepress}

metabolic disorders, particularly diabetes. This journal is indexed on PubMed Central and MedLine. The manuscript management system is completely online and includes a very quick and fair peer-review system, which is all easy to use. Visit http://www.dovepress.com/ testimonials.php to read real quotes from published authors. 